\title{
Experimental study on indoor environment quality in a naturally ventilated classroom of a university using natural ventilation and ventilation fan
}

\author{
Jie Zong ${ }^{1}$, Wenjun $\mathrm{He}^{1}$, Lingna Wang ${ }^{1}$, Hongkai Chai ${ }^{1}$, Yingying Zhao ${ }^{1}$, and Jiying Liu ${ }^{1,2^{*}}$ \\ ${ }^{1}$ School of Thermal Engineering, Shandong Jianzhu University, Jinan 250101, China \\ ${ }^{2}$ Shandong Province Green Building Collaborative Innovation Center, Jinan 250101, China
}

\begin{abstract}
Strengthening indoor ventilation is an important measure to improve air quality. In transitional season between spring and summer, a university classroom in Jinan city was selected as the research object. Mechanical air supply is adopted to solve the problem of insufficient fresh air or excessive carbon dioxide concentration in the classroom. $\mathrm{CO}_{2}$ concentration and air change rates are compared in natural ventilation and mechanical classrooms. The experiment shows that the indoor $\mathrm{CO}_{2}$ concentration of mechanical ventilation classroom is relatively low. Under natural ventilation, mechanical ventilation and mixed ventilation, the average air change rates were $1.05 \mathrm{~h}^{-1}, 1.83 \mathrm{~h}^{-1}$ and $2.7 \mathrm{~h}^{-1}$, respectively. According to the statistics analysis of the questionnaire, $72.84 \%$ of the students hope to install the mechanical ventilation in the classroom
\end{abstract}

\section{Introduction}

$\mathrm{CO}_{2}$ concentration and outdoor air ventilation rate are two key indicators for indoor air environment assessment [1-4]. However, there is no clear standard of the minimum outdoor air rate and the maximum $\mathrm{CO}_{2}$ concentration to satisfy students' comfort in Chinese university classrooms [5]. Domestic and foreign scholars have done some studies on indoor $\mathrm{CO}_{2}$ concentration and outdoor air rates. Turanjanin et al. [6] measured ventilation rates in five naturally ventilated schools in Serbia with a conclusion that the ventilation is inadequate during the heating period. Bakó-Biró et al. [7] studied the effect of classroom ventilation on pupils' performance and found that the low ventilation rates in the classroom can significantly reduce pupils' attention and vigilance. Park et al. [8] studied the appropriate capacity of Korean classroom ventilation system based on air permeability to obtain the optimal design conditions of the ventilation system.

At present, most university classrooms only considered natural ventilation. Due to dense students, only natural ventilation cannot solve the problem of insufficient fresh air in the classroom [9]. Therefore, this study adopt the mechanical ventilation to pursuit the indoor environment quality of classroom. The $\mathrm{CO}_{2}$ concentration, indoor air temperature and humidity in mechanically ventilated and naturally ventilated classrooms were compared. Meanwhile, the questionnaire surveys were conducted in classroom. The purpose of this study is to analyze the indoor environment quality of a university classroom in transitional season between spring and summer in Jinan city.

\section{Experimental methods}

\subsection{Experimental subjects}

This experiment chosen the teaching building of Shandong Jianzhu University as the test object. There is no outdoor air system in this teaching building, and the main way of ventilation is to open windows. At the beginning of the test, the detailed usage of the classroom in the whole teaching building was investigated, and Room No. 213 classroom was selected as mechanical ventilation classrooms. The classroom can accommodate 90 people, and the students and teachers in the classroom are usually exposed to unacceptable bad air quality. The concentration of carbon dioxide is as high as $5000 \mathrm{ppm}$, which is much higher than the average recommended level of $1500 \mathrm{ppm}$ and the preferred level of $1000 \mathrm{ppm}$. The test time was selected in April 2019. The monthly average temperature was $16.2^{\circ} \mathrm{C}$. The main reason for selecting the test in the transition season is that fresh air can be directly introduced outdoors without heat treatment or cold treatment, so the supply air temperature is more suitable. Fig. 1 is the plan of the mechanical ventilation classroom.

\subsection{Experiment introduction}

The experiment includes indoor $\mathrm{CO}_{2}$ concentration, temperature and humidity (including the temperature and

\footnotetext{
* Corresponding author: jx183@sdjzu.edu.cn
} 
humidity of the fan inlet and outlet), air velocity, black globe temperature, etc. The number of student in classroom, the opening area of doors and windows, and the starting time and stopping time of fans are recorded. The ventilation system is placed outdoors, and fresh air is directly supplied by a pipe system with a diameter of $150 \mathrm{~mm}$. It enters the classroom through the opening of the window. The air supply outlet is arranged in the center of the classroom. The air supply is a square diffuser with a fan outlet of $300 \times 300 \mathrm{~mm}$. The air supply capacity is $313 \mathrm{~m}^{3} / \mathrm{h}$ in the form of the topsupplying. Table 1 is the test instruments details.

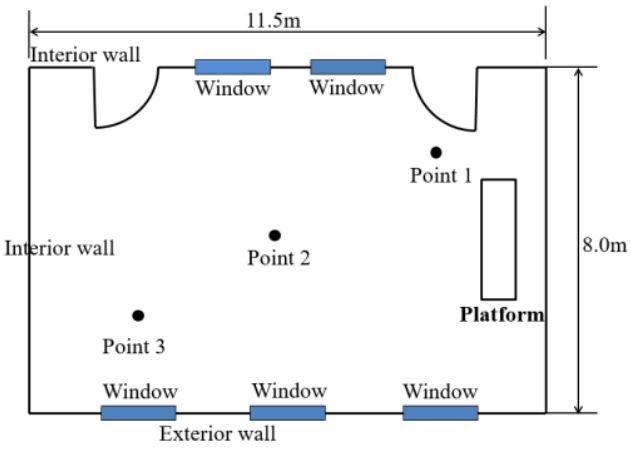

Fig. 1. Plan view of Room No. 213.

Table 1. Instruments used in the field survey.

\begin{tabular}{|c|c|c|c|}
\hline Parameters & Instrument & Range & Accuracy \\
\hline $\mathrm{CO}_{2}$ & TSI & $0 \sim 5000 \mathrm{ppm}$ & $\pm 50 \mathrm{ppm}$ \\
\hline Air temperature & iButton & $-20 \sim 85^{\circ} \mathrm{C}$ & $\pm 0.0625^{\circ} \mathrm{C}$ \\
\hline Relative humidity & iButton & $0 \sim 100 \%$ & $\pm 0.04 \%$ \\
\hline Radiation Temperature & KIMO BN-150-45 & $0 \sim 60^{\circ} \mathrm{C}$ & $\pm 0.2^{\circ} \mathrm{C}$ \\
\hline Regional air velocity & Swema 3000 & $0 \sim 100 \mathrm{~m} / \mathrm{s}$ & $0.1 \mathrm{~m} / \mathrm{s}$ \\
\hline
\end{tabular}

According to the requirements for indoor air sampling points in the Standard for Indoor Air Quality (GB/T1883-2002), the test instruments are placed on the bracket, three carbon dioxide sampling points are arranged in the classroom under test, and three sampling points are diagonally distributed in the classroom crowd. The height of sampling points is $1.1 \mathrm{~m}$, that is, the position of human breathing belt under sitting posture. The iButton temperature sensors are directly attached to the air duct of the inlet and outlet to measure temperature and humidity accurately because of its compact and portable characteristics. The black globe thermometer and anemometer are also placed on the bracket and in the undisturbed classroom aisle. The data were recorded every 30 seconds. Instrument layout and indoor environment of the test room are shown in Fig. 2.

\subsection{Questionnaire}

In order to fully understand the students' satisfaction with the thermal environment in natural and mechanical ventilation classrooms, questionnaires were distributed to students in this teaching building. The undergraduate students' ages were 18-22. The main content of the questionnaire includes the students' satisfaction with the current classroom thermal sensation, air quality, relatively humidity and so on. Because the previous environment may affect students' subjective evaluation, subjects can fill in the questionnaire at least 30 minutes after sitting in the classroom. A total of 868 valid questionnaires were collected after removing the samples of physical discomfort.

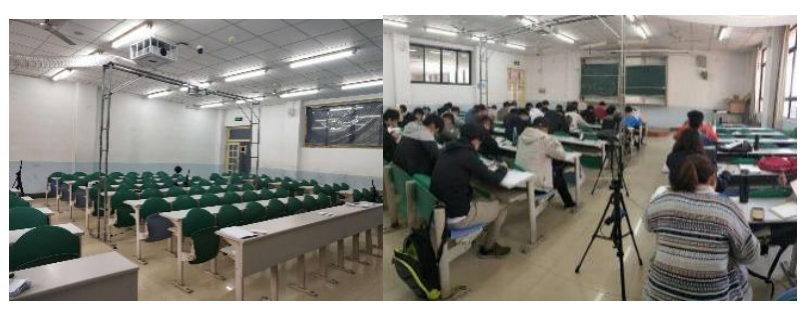

Fig. 2. Instruments used in the experiment and indoor environment condition in the classroom

\subsection{Air change rate calculation}

Based on conservation of mass, the individual step increase of $\mathrm{CO}_{2}$ concentration within time interval $\Delta \tau$ can be formulated as ${ }^{[10]}$ :

$$
\begin{gathered}
\Delta \mathrm{c}=(\Delta \tau / \mathrm{V}) \cdot\left[F 10^{6}-A C H \cdot V \cdot\left(\mathrm{C}_{1}-\mathrm{C}_{0}\right)\right] \\
F=R Q \cdot 0.00201 \cdot H^{0.725} \cdot W^{0.425} \mathrm{M} /(0.23 \cdot \mathrm{RQ}+0.77)
\end{gathered}
$$

where $\Delta \mathrm{C}$ is the unit concentration change (ppm), $\Delta \tau$ is the unit time interval $(\mathrm{h}), \mathrm{V}$ is the volume of the zone $\left(\mathrm{m}^{3}\right), \mathrm{F}$ is the emission rate of $\mathrm{CO}_{2}\left(\mathrm{~m}^{3} / \mathrm{h}\right), \mathrm{ACH}$ is the air change rate $\left(\mathrm{h}^{-1}\right), \mathrm{C}_{1}$ is initial $\mathrm{CO}_{2}$ concentration of time interval $\Delta \tau(\mathrm{ppm})$ and $\mathrm{C}_{0}$ is outdoor $\mathrm{CO}_{2}$ concentration (ppm). where $\mathrm{F}$ is the emission rate of $\mathrm{CO}_{2}$ $\left(\mathrm{m}^{3} / \mathrm{h}\right), \mathrm{RQ}$ is a respiratory quotient, which is generally assumed to be $0.83, \mathrm{H}$ is the height of occupant(m), $\mathrm{W}$ is the weight $(\mathrm{kg}), \mathrm{M}$ is the metabolic level (met).

\section{Results}

\section{$3.1 \mathrm{CO}_{2}$ concentration}

Taking the $\mathrm{CO}_{2}$ test data of April 16 as an example, as shown in Fig. 3, there was no fan at 7:30-17:00, and 18:20-21:00 was the time period of fan opening. It can be seen from the figure that the indoor $\mathrm{CO}_{2}$ 
concentration can be significantly reduced when the fan is turned on in a comparable number of cases. About 7:30, people came in one after another, and the concentrate on of $\mathrm{CO}_{2}$ rose from $500 \mathrm{ppm}$ to $4230 \mathrm{ppm}$.

During the period from 9:25 to 9:40, the door of the classroom was opened and the flow of people was frequent, which caused the fluctuation of $\mathrm{CO}_{2}$ concentration. In the afternoon, the concentration of $\mathrm{CO}_{2}$ is low because of the small number of students attending classes. At 18:20, people began to enter one after another, and the concentration of $\mathrm{CO}_{2}$ gradually increased. When windows were opened at 20:00 and mixed air supply was carried out, $\mathrm{CO}_{2}$ concentration decreased gradually. The results show that the indoor $\mathrm{CO}_{2}$ concentration of mechanical ventilation classroom is relatively low, and the improvement of indoor environmental quality is more obvious by mixed air supply.

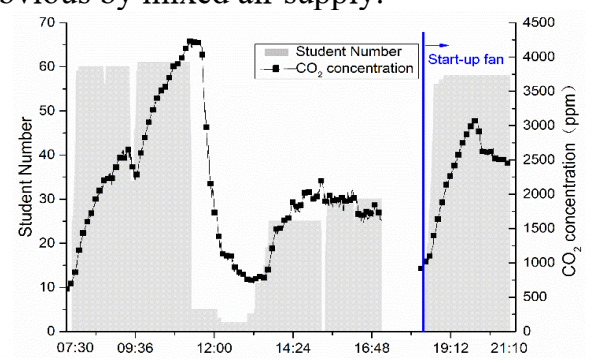

Fig. 3. Variation of $\mathrm{CO} 2$ concentration and population.

\subsection{Indoor air temperature and humidity}

Fig. 4 shows the temperature and humidity distribution curve in the classroom on April 27. The temperature distribution curve is shown in Fig. 4 (a). The overall temperature curve in the classroom shows an upward trend, with the highest temperature reaching $22.6^{\circ} \mathrm{C}$ and the average temperature reaching $21.16^{\circ} \mathrm{C}$. Because of the dense population in the middle of the classroom, the temperature was relatively high. The temperature fluctuated between 9:25 and 9:45, which was caused by the movement of people after class. Because the temperature measurement button of the inlet was placed in the indoor ventilation duct, the temperature was too high before the fan was turned on.
After the fan was turned on, the temperature of the inlet decreased rapidly with the introduction of outdoor fresh air, but the temperature of the classroom and the temperature of the inlet were still about $2^{\circ} \mathrm{C}$ different due to the indoor environmental impact. The relative humidity distribution curve is shown in Fig. 4 (b). The relative humidity curve and the temperature curve show the opposite trend. The indoor average relative humidity is $38 \%$. The day of April 27 was cloudy, so the relative humidity of the fan inlet was higher. After opening the fan, the air flow in the pipe accelerated, which reduced the relative humidity of the inlet and outlet.

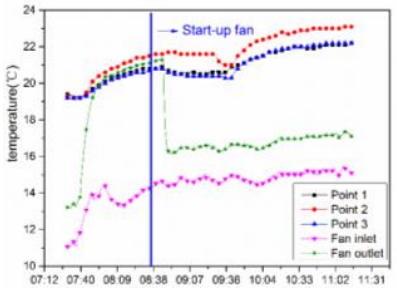

(a)

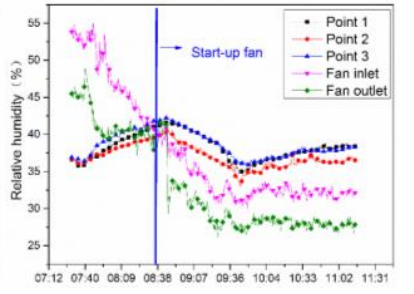

(b)
Fig. 4. Indoor air temperature variaiton (a) and relative humidity varaiton (b).

\section{$3.3 \mathrm{CO}_{2}$ in classroom}

Table 2 shows the air change rate calculated according to the actual situation of the classroom. The number of air change rate is the combined effect of fan, window opening and occupant density. For April 27, the smaller the density of personnel, the greater the number of air change rate. When mixing ventilation, air change rate is above $2 \mathrm{~h}^{-1}$, and the number of air change rate depends on the windows opening time. The longer the window opening time is, the more the window opening is, and the greater the air change rate is. Under natural ventilation, mechanical ventilation and mixed ventilation, the average air change rate were $1.05 \mathrm{~h}^{-1}, 1.83 \mathrm{~h}^{-1}$ and $2.7 \mathrm{~h}^{-1}$, respectively. When the window was not opened on April 12 , the air change rate was only $0.71 \mathrm{~h}^{-1}$. It can be seen that mechanical ventilation can significantly increase indoor ventilation, so that students are not exposed to high $\mathrm{CO}_{2}$ concentration.

Table 2. Air change rate in classroom

\begin{tabular}{|c|c|c|c|c|c|}
\hline \multirow{2}{*}{ Date } & Time & $\begin{array}{c}\text { Fan } \\
\text { /window }\end{array}$ & $\begin{array}{c}\text { Student } \\
\text { no. }\end{array}$ & Mode & ACH \\
\hline \multirow{3}{*}{ Apr.12 } & $9: 30-11: 10$ & Window on & 60 & NV & 1.25 \\
\cline { 2 - 6 } & $11: 30-12: 00$ & No & 60 & NV & 0.71 \\
\cline { 2 - 6 } Apr.14 & $13: 30-16: 15$ & Both on & 80 & MIV & 2.71 \\
\cline { 2 - 6 } & $13: 30-15: 00$ & $\begin{array}{c}\text { Fan on }, \\
\text { window 15min }\end{array}$ & 40 & MIV & 2.56 \\
\hline \multirow{2}{*}{ Apr.16 } & $15: 30-16: 50$ & Fan on & 39 & MV & 1.5 \\
\cline { 2 - 6 } & $7: 30-12: 00$ & Window 15min & 60 & NV & 1.18 \\
\hline \multirow{2}{*}{ Apr.23 } & $19: 00-21: 00$ & Fan on & 59 & MV & 1.6 \\
\hline \multirow{2}{*}{ Apr.24 } & $18: 40-21: 00$ & $\begin{array}{c}\text { Fan on, } \\
\text { window on }\end{array}$ & 40 & MIV & 2.43 \\
\hline \multirow{2}{*}{ Apr.27 } & $7: 40-21: 00$ & $\begin{array}{c}\text { Fan on, } \\
\text { window on }\end{array}$ & 35 & MV & 3.1 \\
\cline { 2 - 6 } & $9: 45-11: 15$ & Fan on & 21 & MV & 2.28 \\
\hline
\end{tabular}




\section{Analysis of questionnaire}

\subsection{Evaluation natural and fan ventilation}

The evaluation of indoor air quality, temperature and thermal comfort in natural and mechanical ventilation classrooms is shown in Fig. 5. As can be seen, for the comparison of air freshness, most people in the mechanical ventilation classroom feel fresher. The number of people who feel sultry is less than $1 / 3$ of the number in natural ventilation classroom. There is little difference between feeling fine and feeling a little stuffy. By contrast, the air in the mechanically ventilated classroom is fresher. For the comparison of indoor temperature, the number who feel moderate temperature in mechanical ventilation classroom is far greater than that in natural ventilation classroom, accounting for $50.5 \%$.

Fewer people feel hot when the indoor temperature is slightly higher. Many people feel little hot or little cold. For the reasons, first, only one diffuser is arranged in the classroom, the indoor air blow is uneven, which cause a little cold near the air outlet and a little hot far off the air outlet. Second, due to individual differences, the evaluation standard for thermal sensation are different, causing some feeling cold and some feeling hot. For the comparison of indoor thermal comfort, the number in mechanical ventilation classroom feels more comfortable than the number in natural ventilation classroom, and the discomfort evaluation is relatively less.

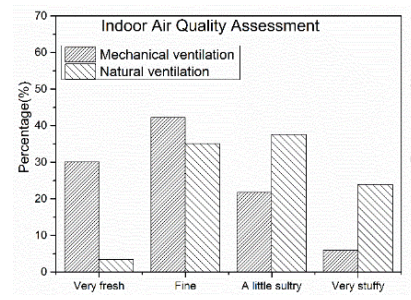

(a)

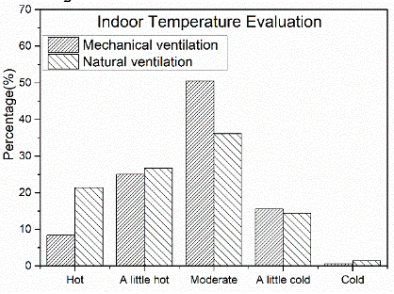

(b)

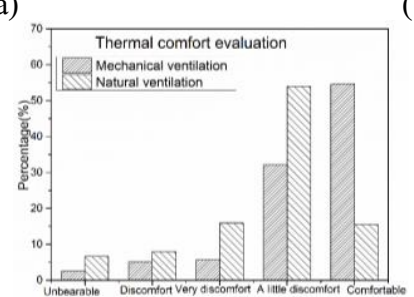

(c)

Fig. 5. The subjects vote of indoor air quality (a), temperature (b) and thermal comfort (c) in natural and mechanical ventilation classrooms

\subsection{Evaluation of natural and fan ventilation}

In order to better understand the needs of students and provide students with a better and comfortable learning environment, a survey related to occupant feeling was conducted. According to the current situation of classroom ventilation, through the question "What factors will make you feel more comfortable in the room?" The survey results are shown in Fig. 6. 35.51\% chose "the change of fresh air", and fewer chose "the wind speed", "temperature and humidity". It shows that improving indoor air freshness (increasing air ventilation) during the transitional season is an urgent need of students. It also shows that there are serious ventilation problems in the existing classrooms. In addition, through willingness questionnaire for installing fan, $72.84 \%$ of students thought it important to install fan in classroom.

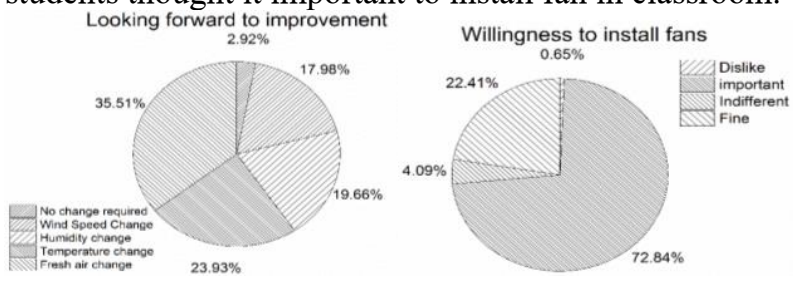

Fig. 6. Results for motion for looking forward to improvements in the classroom (a) and the willingness to install fans (b).

\section{Conclusions}

This study conducted an on-site experiment to investigate the indoor environment quality in a naturally ventilated classroom of a university using natural ventilation and ventilation fan. The $\mathrm{CO}_{2}$ concentration, indoor air temperature and humidity in mechanically ventilated and naturally ventilated classrooms were compared. Meanwhile, the questionnaire surveys were conducted in classroom. The results show that once the fan is turned on, the growth rate of $\mathrm{CO}_{2}$ concentration in classroom slows down but still exceeds 2000 ppm. Because the actual air volume of the fresh air fan can't meet the design requirements, and the indoor students' density is high, the mechanical ventilation is insufficient. The $\mathrm{CO}_{2}$ concentration still exceeds the 2000ppm. Therefore, ventilation can be carried out in a mixed manner. The opening of fans and windows and the student number can affect air change rate. Under natural ventilation, mechanical ventilation and mixed ventilation, the average air change rates were $1.05 \mathrm{~h}^{-1}, 1.83 \mathrm{~h}^{-1}$ and $2.7 \mathrm{~h}^{-1}$, respectively. The longer the window opening time is, the larger air change rate is. According to the results of the questionnaire survey, $35.51 \%$ of the students want to improve the air freshness of the classroom, and $72.84 \%$ of the students hope to install fresh air fans in the classroom. Therefore, it is very necessary to use mechanical ventilation as an auxiliary tool of classroom ventilation in the universities classroom to provide comfortable environment and sufficient fresh air for students.

\section{Acknowledgements}

This work was supported by the National Natural Science Foundation of China (51608310) and Support Plan for Outstanding Youth Innovation Team in Shandong Province (2019KJG005), Students' Research and Training Project of School of Thermal Engineering in Shandong Jianzhu University (SRTP-201810). 


\section{References}

1. $\mathrm{P}$ Kapalo, $\mathrm{P}$ Siroczki, International Journal of Ventilation 1312 (2014)

2. J Liu, S Zhu, M K Kim, J Srebric, Sustainability 11 4166 (2019)

3. Z Li, K Li, J Chang, H Wu, J Liu, IOP Conference Series: Materials Science and Engineering 609 042016 (2019)

4. J Liu, D A Dalgo, S Zhu, H Li, L Zhang, J Srebric, Building Simulation 12905 (2019)

5. S Batterman, International Journal of Environmental Research and Public Health 14145 (2017)

6. V Turanjanin, B Vučićević, M Jovanović, N Mirkov, I Lazović, Energy 77290 (2014)

7. Z Bakó-Biró, D J Clements-Croome, N Kochhar, H B Awbi, M J Williams, Building and Environment 48215 (2012)

8. PARK, Jonghoon, JANG, Yongsung, AHN, Youngchull, CHEONG, Seongir, LEE, Jaekeun, Journal of Mechanical Science and Technology 22 788 (2008)

9. P V Dorizas, M N Assimakopoulos, C Helmis, M Santamouris, Science of the Total Environment $\mathbf{5 0 2}$ 557 (2015)

10. J Hou, Y Zhang, Y Sun, W Pan, Q Zhang, X Kong, J Sundell, Building and Environment 132273 (2018) 